\title{
Effects of resistant maltodextrin on bowel movements: a systematic review and meta-analysis
}

This article was published in the following Dove Press journal:

Clinical and Experimental Gastroenterology

\author{
Norikazu Watanabe' \\ Masataka Suzuki' \\ Yoshitake Yamaguchi \\ Yukari Egashira ${ }^{3}$ \\ 'Yakujihou Marketing Jimusho Co \\ Ltd., Tokyo, ${ }^{2}$ Research Laboratory, \\ Matsutani Chemical Industry Co \\ Ltd., Hyogo, ${ }^{3}$ Laboratory of Food \\ and Nutrition, Graduate School of \\ Horticulture, Chiba University, Chiba, \\ Japan
}

\begin{abstract}
It is well known that dietary fiber helps to relieve and prevent constipation, and there are a number of scientific papers, including systematic reviews and meta-analyses on the effects of naturally derived dietary fiber on bowel movements. In recent years, there has been an increase in the manufacture of dietary fiber ingredients obtained from food raw materials, and these are now commonly available in the market. Resistant maltodextrin (RMD), a soluble dietary fiber, is manufactured from starch, and industrially produced soluble dietary fiber is used worldwide. While there are many reports on the effects of RMD on bowel movements, no systematic review or meta-analysis has been reported. We conducted a systematic review and meta-analysis to clarify the effect of RMD on bowel movements based on stool frequency and stool volume. We also investigated the subjective evaluation of RMD effects on bowel movements. Of a total of 314 potentially relevant articles, 28 articles met the eligibility criteria, and 29 randomized controlled trials were identified. As a result of integration analyses, we found that the intake of RMD significantly increased stool volume and stool frequency compared with placebo intake. Furthermore, RMD intake tended to improve sensation of complete/incomplete evacuation. In conclusion, the evidence suggests that RMD has a positive effect on bowel movements, contributing to normal bowel function. This finding will help in the development of new criteria for choice of dietary fiber in the process of developing food products.
\end{abstract}

Keywords: resistant maltodextrin, dietary fiber, bowel movement, systematic review, meta-analysis

\section{Introduction}

Reports indicate that $\sim 20 \%$ of the population worldwide suffers from constipation, and the rate is higher in developed countries, including the USA, the UK, and Japan. ${ }^{2-4}$ According to the Rome III diagnostic criteria, the World Gastroenterology Organization defined constipation as the presence of at least two of the following in patients who do not take laxatives in any 12-week period during the previous 12 months: 1) fewer than three bowel movements per week; 2) hard stool in $>25 \%$ of bowel movements; 3 ) a sense of incomplete evacuation in $>25 \%$ of bowel movements; 4) excessive straining in $>25 \%$ of bowel movements; and 5) a need for digital manipulation to facilitate evacuation. ${ }^{5}$ Constipation causes feelings of fatigue and weariness, adversely affects various daily activities, and reduces labor productivity. ${ }^{6}$ Constipation could be induced by lifestyle habits, specifically diets containing substantially processed food and/or a lack of exercise. Elderly people and pregnant women, in particular, are prone to constipation. It has been reported that chronic constipation could increase the risk
Correspondence: Norikazu Watanabe Yakujihou Marketing Jimusho Co Ltd., 2-16-26-80I Ohashi,

Meguro, Tokyo 153-0044, Japan

Tel $+8 \mid 368693452$

Fax +81368697072

Email watanabe@yakujihou-marketing. co.jp 
of cancer of the large intestine and reduce survival rate. ${ }^{7,8}$ Therefore, it is postulated that the maintenance of normal defecation contributes significantly to human health and the quality of life.

It has been known that intake of dietary fiber helps to relieve and prevent constipation. Hippocrates, an ancient Greek physician, recorded the use of "wheat bran" as a laxative agent over 2000 years ago, and dietary fiber has received considerable attention through the ages. ${ }^{9}$ In the early 1970s, Burkitt reported "the dietary fiber hypothesis" of colon cancer. ${ }^{10}$ Since then, the research of dietary fibers has advanced significantly worldwide, and the mechanisms underlying the effectiveness of dietary fiber against constipation have been reported. Consequently, the European Food Safety Authority (EFSA) recommends consuming $25 \mathrm{~g}$ of dietary fiber a day for normal laxation. ${ }^{11}$ However, actual daily consumption of dietary fiber is less than the recommended amount in many European countries, ${ }^{12}$ in the USA, Japan, and other developed countries. ${ }^{13,14}$ As it is not easy to consume the adequate amount of dietary fiber from daily meals, the use of added manufactured fiber will be a strategy to increase fiber ingredients available on the market.

Dietary fiber is categorized into two types: soluble dietary fiber (eg, partially hydrolyzed guar gum and resistant maltodextrin [RMD]) and insoluble dietary fiber (eg, wheat bran and resistant starch). Numerous studies have reported that both types of dietary fiber result in improved bowel movements ${ }^{15-18}$ although the underlying mechanisms are different. Soluble dietary fiber is pectized when hydrated and softens the stool, whereas insoluble dietary fiber absorbs water in the intestine and increases the bulk of the stool, which stimulates the bowel wall and enhances peristaltic activity.

In some countries, such as the USA, countries within the European Union, Korea, and Taiwan, there are systems in place for food labeling, indicating the function of foods, such as an improved effect on bowel movements by dietary fiber. In Japan, the system is called Foods for Specified Health Use (FOSHU), ${ }^{19}$ and it has approved the use of 1127 products as of March 2017, including 337 products claiming benefits on gut health, including functional ingredients: RMD (182 products), dietary fiber of psyllium seed husk (35), galactooligosaccharide (16), depolymerized sodium alginate (12), polydextrose (6), partially hydrolyzed guar gum (5), and wheat bran (4). The most widely used ingredient by FOSHU for the maintenance of normal bowel functions is RMD. RMD is also widely used in Korea and Taiwan.

RMD is nonviscous water-soluble dietary fiber derived from starch. Recently, several companies have begun to produce RMD using different raw materials and/or different production processes. The effect of RMD on bowel movements is well documented, ${ }^{20,21}$ although no systematic reviews or meta-analyses have been reported to date. McRorie and Chey conducted a literature review on the physical effects of fiber in the gut and concluded that nonviscous soluble fibers have no benefit on bowel regularity. ${ }^{22}$

In the present study, we conducted a systematic review and meta-analysis to determine the effect of RMD on bowel movements, which we believe will help in the development of new criteria for the choice of dietary fiber in the process of developing food products. We also investigated the subjective evaluation on bowel movements.

\section{Methods}

A systematic review and meta-analysis were performed following the guidelines of the Cochrane Handbook for systematic reviews of interventions ${ }^{23}$ and reported in accordance with the preferred reporting items for systematic reviews and meta-analysis (PRISMA). ${ }^{24}$

We conducted a meta-analysis to evaluate the effect of RMD on bowel movements. Primary parameters were stool frequency and stool volume. Regarding stool frequency, the number of defecations during the study period was recorded. Stool volume was evaluated using two methods: by weight and by visual check. Measuring stool weight generates accurate figures but is a burden on subjects. Therefore, measuring stool by visual check, based on the number of eggs (or ping-pong balls), is often adopted as there is a positive correlation with weight. ${ }^{25}$ The evaluation of stool volume and stool frequency has been validated with the guidance of EFSA $^{26}$ and FOSHU. ${ }^{27}$ Randomized controlled trials (RCTs) evaluating stool volume by visual check were adopted in this meta-analysis study.

\section{Formulation}

The primary question was "Does intake of RMD increase stool volume and stool frequency and improve the bowel movements?" The secondary question was "Does intake of RMD improve subjective evaluation (consistency, color, odor of stool, and sensation of complete/incomplete evacuation)?"

\section{Literature search and study selection}

A comprehensive literature search to identify the effects of RMD on bowel movements was performed up to January 2017 using the following databases: Cochrane Central Register of Controlled Trials, the US National Library of Medicine database (MEDLINE via the PubMed portal), 
Japan Medical Abstracts Society, and the National Institute of Informatics Electronic Library Service and National Diet Library.

The bibliographical search was performed by using three terms: RMD, resistant dextrin, and indigestible dextrin. The bibliographical search in Japanese was performed using the same ingredient name "nan-syoka-sei-dekisutorin" in combination with words related to bowel functions (Table 1).

Eligibility criteria for the primary question were as follows: RCTs that, 1) investigated in the general population, such as healthy adults or adults with a tendency toward constipation, but not receiving medical treatment; 2) did not include pregnant women or lactating women; 3 ) assessed both stool frequency and stool volume; 4) conducted statistical analysis for significance; 5) were designed as double-blind or single-blind studies; 6) received the written informed consent from subjects who fully understood the content of the clinical trial; 7) did not include RMD in the placebo; 8) were published in peer-reviewed original papers; and 9) were reported in English or Japanese language. RCTs were excluded if they, 1) included not only RMD but also other types of dietary fiber in the test food or placebo, and 2) used hydrogenated RMD.

\section{Data extraction}

Two reviewers (NW and MS) extracted the following data based on the eligibility criteria: 1) authors; 2) published years; 3) study design; 4) number of subjects; 5) age; 6) daily intake of RMD; 7) stool frequency and stool volume when test food and placebo were ingested (two occasions); and 8) subjective evaluation.

Both the reviewers independently reviewed the original papers and extracted the data. When the data extracted by the two reviewers did not coincide, they both reviewed the original papers together. When two RCTs were included in one report and each RCT included its own placebo group,

Table I Search formula

International database site: CENTRAL, PubMed

"resistant maltodextrin"

"resistant dextrin"

"indigestible dextrin"

Japanese database site: I-Chu-Shi Web, CiNii

"nan-syoka-sei-dekisutorin" AND "seicho"

"nan-syoka-sei-dekisutorin" AND "haiben”

"nan-syoka-sei-dekisutorin" AND "bentsu"

Notes: "nan-syoka-sei-dekisutorin," [resistant maltodextrin]; "seicho," [intestina regulation]; "haiben," [bowel movement]; "bentsu," [laxation].

Abbreviations: CENTRAL, Cochrane Central Register of Controlled Trials; CiNii, Citations Index Portal; I-Chu-Shi Web, Japan Medical Abstracts Society. they were counted as two RCTs. Units of stool volume and stool frequency were converted to number of stools per 7 days. Standard error was converted to standard deviation.

\section{Risk of bias}

Two reviewers (NW and MS) independently assessed the risk of bias for the following six categories based on the Cochrane Handbook for systematic review of interventions (Version 5.1.0, 2011): ${ }^{23} 1$ ) sequence generation; 2) allocation sequence concealment; 3) blinding of participants and personnel; 4) incomplete outcome data; 5) selective outcome reporting; and 6) other potential threats to validity. The risk of bias for each category was evaluated according to three grades: high risk, unclear risk, and low risk. When the risk of bias assessment by the two reviewers did not coincide, the grade was decided following discussion between the reviewers.

\section{Statistical analysis}

Mean difference (MD) was calculated as a common effect size for stool volume, stool frequency, and subjective evaluation items. When the values were not set out in the paper, inquiries were sent to the corresponding author seeking clarification. Meta-analysis was conducted using the DerSimonianLaird method. Cochran Q-test ( $\chi^{2}$ test) and $I^{2}$ statistic value $\left(0 \% \leq I^{2} \leq 100 \%\right)$ were determined to evaluate heterogeneity. To evaluate the publication bias, data were corrected by the trim and fill method when the funnel plot was asymmetric. Fail-safe $\mathrm{N}$ was calculated to evaluate robustness.

Statistical analysis was performed by using Review Manager Version 5.3.5 (The Nordic Cochrane Centre, The Cochrane Collaboration, London, UK) and Comprehensive MetaAnalysis Version 2.2.064 (BioStat Inc., Englewood, NJ, USA).

\section{Results}

We identified 314 potentially relevant papers. Of these, 28 papers met the eligibility criteria (Figure 1). A study by Ishi et $\mathrm{al}^{31}$ reported two independent RCTs. Therefore, finally, 29 RCTs were adopted in the present study (Table 2).

\section{Risk of bias}

The risk of bias was evaluated for six categories based on the Cochrane Handbook (Table 3).

\section{Sequence generation}

Twenty-six RCTs were classified as "low risk" as they were randomly allocated, ${ }^{20,21,28-35,37-48,51-53}$ while three RCTs were classified as "unclear risk" as the order of allocation was not clear. ${ }^{36,49,50}$ 


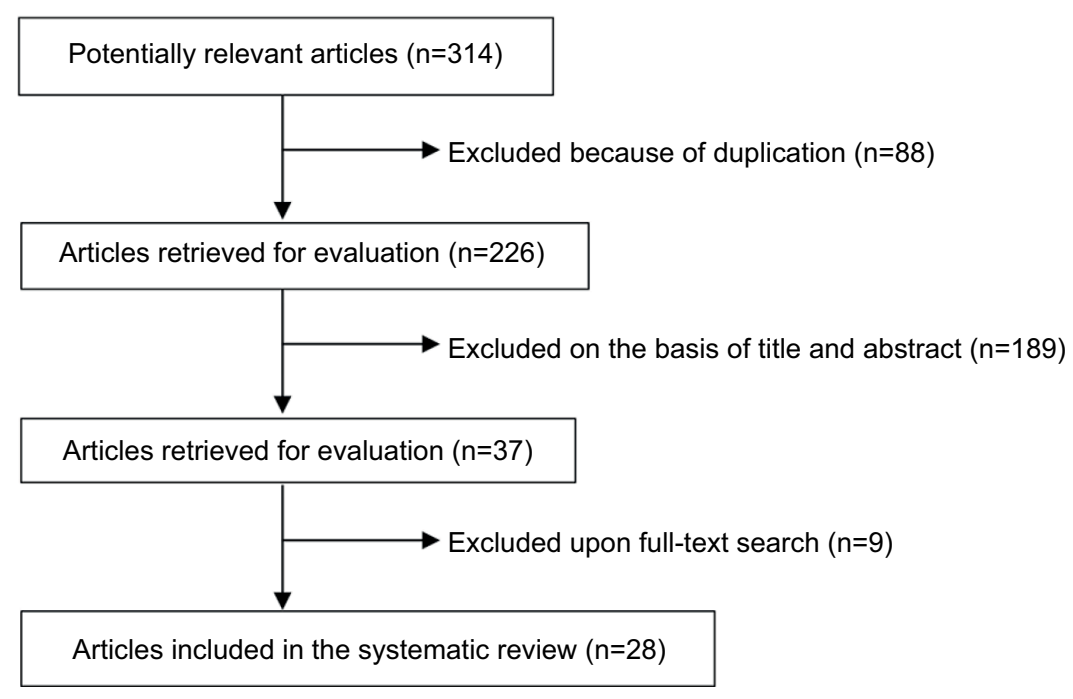

Figure I Flow diagram of study selection.

Table 2 Characteristics of RCTs regarding effect of RMD on the bowel movements

\begin{tabular}{|c|c|c|c|c|c|}
\hline Study & $\begin{array}{l}\text { Study } \\
\text { design }\end{array}$ & $\mathbf{N}(\mathbf{M} / \mathbf{F})$ & Age & $\begin{array}{l}\text { Daily intake of } \\
\operatorname{RMD}(g)^{a}\end{array}$ & $\begin{array}{l}\text { Duration } \\
\text { (day) }\end{array}$ \\
\hline Abellán Ruiz et $\mathrm{al}^{20}$ & DPT & $66(32: 34)$ & $21.3 \pm 2.8$ & 13.5 & 21 \\
\hline Furukawa et $\mathrm{al}^{21}$ & SCT & $40(7: 33)$ & $27.9 \pm 2.7$ & 3.8 & 14 \\
\hline |keguchi et $\mathrm{al}^{28}$ & DCT & $42(0: 42)$ & $28.2 \pm 6.1$ & 4.4 & 14 \\
\hline Inafuku et $\mathrm{al}^{29}$ & DCT & $54(12: 42)$ & $37 \pm 1.5$ & 7.0 & 14 \\
\hline Inagi et $\mathrm{al}^{30}$ & SCT & $47(0: 47)$ & $21.3 \pm 0.7$ & 4.6 & 14 \\
\hline Ishi et $\mathrm{al}^{3 \mathrm{lb}}$ & SCT & $40(0: 40)$ & 43.3 & 5.0 & 20 \\
\hline Ishi et $\mathrm{al}^{3 \mathrm{lc}}$ & SCT & $40(0: 40)$ & 43.3 & 5.0 & 20 \\
\hline Ito et $\mathrm{al}^{32}$ & DCT & $56(8: 48)$ & $36.7 \pm 5.9$ & 5.1 & 14 \\
\hline Kasagi et $\mathrm{al}^{33}$ & SCT & $46(2: 44)$ & $20.2 \pm 1.4$ & 5.0 & 14 \\
\hline Kishimoto et al ${ }^{34}$ & SCT & $38(0: 38)$ & $19.8 \pm 0.9$ & 4.2 & 14 \\
\hline Kusaba et $\mathrm{al}^{35}$ & DCT & $50(8: 42)$ & M: 40.5, F: 36.3 & 5.1 & 14 \\
\hline Nakamura et al ${ }^{36}$ & SCT & $30(0: 30)$ & $20-22$ & 5.3 & 20 \\
\hline Nakamura et a ${ }^{37}$ & SCT & $30(0: 30)$ & $20-22$ & 5.0 & 20 \\
\hline Sato et $\mathrm{a}^{38}$ & DCT & $28(0: 28)$ & 23.7 & 4.8 & 14 \\
\hline Sato et $\mathrm{al}^{39}$ & DCT & $29(0: 29)$ & 24.8 & 4.8 & 14 \\
\hline Seno et $\mathrm{al}^{40}$ & SCT & $39(2: 37)$ & $39.9 \pm 11.5$ & 4.8 & 14 \\
\hline Shimabukuro et $\mathrm{al}^{41}$ & SCT & $28(12: 16)$ & M: 47.8, F: 40.I & 5.2 & 20 \\
\hline Takagaki et al ${ }^{42}$ & SCT & 71 (38:33) & $28.4 \pm 8.1$ & 5.1 & 14 \\
\hline Takagaki et al ${ }^{43}$ & DCT & $40(0: 40)$ & $37.0 \pm 12.2$ & 5.1 & 14 \\
\hline Tanahashi et al ${ }^{44}$ & DCT & $4 I(0: 4 I)$ & $30.4 \pm 4.5$ & 4.7 & 10 \\
\hline Tanaka et $\mathrm{al}^{45}$ & SCT & $22(0: 22)$ & $23.1 \pm 4.3$ & 5.9 & 14 \\
\hline Tanaka et $\mathrm{al}^{46}$ & SCT & $40(0: 40)$ & $20-58$ & 6.2 & 14 \\
\hline Taniguchi et $\mathrm{al}^{47}$ & SCT & $40(14: 26)$ & $23.0 \pm 3.2$ & 5.0 & 10 \\
\hline Umagami et $\mathrm{al}^{48}$ & DCT & $32(10: 22)$ & M: 35, F: 38 & 5.7 & 20 \\
\hline Umekawa et al ${ }^{49}$ & SCT & $27(6: 2 I)$ & $30.1 \pm 7.9$ & 5.0 & 10 \\
\hline Unno et $\mathrm{a}^{50}$ & $\mathrm{CT}$ & $84(58: 26)$ & Undescribed & 4.2 & 14 \\
\hline Unno et $\mathrm{a}^{51}$ & SCT & $42(0: 42)$ & $2|-4|$ & 4.8 & 14 \\
\hline Unno et $\mathrm{al}^{52}$ & SCT & $37(13: 24)$ & $23-44$ & 5.3 & 14 \\
\hline Yamamoto et $a^{53}$ & $\mathrm{CT}$ & $29(6: 23)$ & M: 44.7, F: 30.1 & 7.7 & 7 \\
\hline
\end{tabular}

Notes: ${ }^{a}$ Amount as dietary fiber; 'bubstudy I; 'substudy 2.

Abbreviations: CT, crossover trial; DCT, double-blind crossover trial; DPT, double-blind parallel-group trial; F, female; M, male; RCT, randomized controlled trial; RMD, resistant maltodextrin; SCT, single-blind crossover trial. 
Table 3 Risk of bias of RCTs regarding effect of RMD on the bowel movements

\begin{tabular}{|c|c|c|c|c|c|c|}
\hline Study & $\begin{array}{l}\text { Sequence } \\
\text { generation }\end{array}$ & $\begin{array}{l}\text { Allocation } \\
\text { sequence } \\
\text { concealment }\end{array}$ & $\begin{array}{l}\text { Blinding of } \\
\text { participants and } \\
\text { personnel }\end{array}$ & $\begin{array}{l}\text { Incomplete } \\
\text { outcome } \\
\text { data }\end{array}$ & $\begin{array}{l}\text { Selective } \\
\text { outcome } \\
\text { reporting }\end{array}$ & $\begin{array}{l}\text { Other potential } \\
\text { threats to } \\
\text { validity }\end{array}$ \\
\hline Abellán Ruiz et al ${ }^{20}$ & Low risk & Low risk & Low risk & Low risk & Low risk & Low risk \\
\hline Furukawa et $\mathrm{al}^{21}$ & Low risk & Low risk & Unclear risk & Low risk & Low risk & Low risk \\
\hline Ikeguchi et $\mathrm{al}^{28}$ & Low risk & Low risk & Low risk & Low risk & Low risk & Low risk \\
\hline Inafuku et $\mathrm{al}^{29}$ & Low risk & Low risk & Low risk & Low risk & Low risk & Low risk \\
\hline Inagi et $\mathrm{al}^{30}$ & Low risk & Low risk & Unclear risk & Low risk & Low risk & Low risk \\
\hline Ishi et $\mathrm{al}^{3 \mathrm{la}}$ & Low risk & Low risk & Unclear risk & Low risk & Low risk & Low risk \\
\hline Ishi et $\mathrm{al}^{3 \mathrm{Ib}}$ & Low risk & Low risk & Unclear risk & Low risk & Low risk & Low risk \\
\hline Ito et $\mathrm{al}^{32}$ & Low risk & Low risk & Low risk & Low risk & Low risk & Low risk \\
\hline Kasagi et $\mathrm{al}^{33}$ & Low risk & Low risk & Unclear risk & Low risk & Low risk & Low risk \\
\hline Kishimoto et $\mathrm{al}^{34}$ & Low risk & Low risk & Unclear risk & Low risk & Low risk & Low risk \\
\hline Kusaba et $\mathrm{al}^{35}$ & Low risk & Low risk & Low risk & Low risk & Low risk & Low risk \\
\hline Nakamura et $\mathrm{al}^{36}$ & Unclear risk & Low risk & Unclear risk & Low risk & Low risk & Low risk \\
\hline Nakamura et $\mathrm{al}^{37}$ & Low risk & Low risk & Unclear risk & Low risk & Low risk & Low risk \\
\hline Sato et $\mathrm{a}^{38}$ & Low risk & Low risk & Low risk & Low risk & Low risk & Low risk \\
\hline Sato et $\mathrm{al}^{39}$ & Low risk & Low risk & Low risk & Low risk & Low risk & Low risk \\
\hline Seno et $\mathrm{al}^{40}$ & Low risk & Low risk & Unclear risk & Low risk & Low risk & Low risk \\
\hline Shimabukuro et $\mathrm{al}^{4 \text { I }}$ & Low risk & Low risk & Unclear risk & Low risk & Low risk & Low risk \\
\hline Takagaki et al $^{42}$ & Low risk & Low risk & Unclear risk & Low risk & Low risk & Low risk \\
\hline Takagaki et $\mathrm{al}^{43}$ & Low risk & Low risk & Low risk & Low risk & Low risk & Low risk \\
\hline Tanahashi et $\mathrm{al}^{44}$ & Low risk & Unclear risk & Low risk & Low risk & Low risk & Low risk \\
\hline Tanaka et $\mathrm{al}^{45}$ & Low risk & Low risk & Unclear risk & Low risk & Low risk & Low risk \\
\hline Tanaka et $\mathrm{al}^{46}$ & Low risk & Low risk & Unclear risk & Low risk & Low risk & Low risk \\
\hline Taniguchi et $\mathrm{al}^{47}$ & Low risk & Low risk & Unclear risk & Low risk & Low risk & Low risk \\
\hline Umagami et $\mathrm{al}^{48}$ & Low risk & Low risk & Low risk & Low risk & Low risk & Low risk \\
\hline Umekawa et al ${ }^{49}$ & Unclear risk & Low risk & Unclear risk & Low risk & Low risk & Low risk \\
\hline Unno et $\mathrm{al}^{50}$ & Unclear risk & Low risk & Unclear risk & Low risk & Low risk & Low risk \\
\hline Unno et $a^{51}$ & Low risk & Low risk & Unclear risk & Low risk & Low risk & Low risk \\
\hline Unno et $\mathrm{al}^{52}$ & Low risk & Low risk & Unclear risk & Low risk & Low risk & Low risk \\
\hline Yamamoto et $\mathrm{al}^{53}$ & Low risk & Unclear risk & Unclear risk & Low risk & Low risk & Low risk \\
\hline
\end{tabular}

Notes: aSubstudy I; ' substudy 2.

Abbreviations: RCT, randomized controlled trial; RMD, resistant maltodextrin.

\section{Allocation sequence concealment}

Twenty-seven RCTs were classified as "low risk" as the allocation sequence was appropriately concealed, ${ }^{20,21,28-43,45-52}$ while two RCTs were classified as "unclear risk" as allocation concealment was not clear. ${ }^{44,53}$

\section{Blinding of participants and personnel}

Ten RCTs were classified as "low risk" as they were designed as blind clinical trials, ${ }^{20,28,29,32,35,38,39,43,44,48}$ while 19 RCTs were classified as "unclear risk" as it was not clear whether they were blind clinical trials. ${ }^{21,30,31,33,34,36,37,40-42,45-47,49-53}$

\section{Incomplete outcome data}

All RCTs were classified as "low risk" as the number of dropouts and the reasons for dropouts were comparable between the test and placebo groups. ${ }^{20,21,28-53}$

\section{Selective outcome reporting}

All RCTs were classified as "low risk" as they were analyzed and reported as planned in the methodology. ${ }^{20,21,28-53}$

\section{Other potential threats to validity}

All RCTs were classified as "low risk" as they did not have any other biases. ${ }^{20,21,28-53}$

\section{Primary question: effects on bowel movements}

Integration analyses revealed that intake of RMD significantly increased stool volume compared with placebo intake (MD $=1.65,95 \%$ confidence interval $[\mathrm{CI}][1.10,2.20], p<0.00001)$, and its heterogeneity was low $\left(I^{2}=13 \%, p=0.27\right.$; Figure 2$)$. Intake of RMD also significantly increased stool frequency compared with placebo (MD $=0.71,95 \%$ CI $[0.48,0.94]$, 


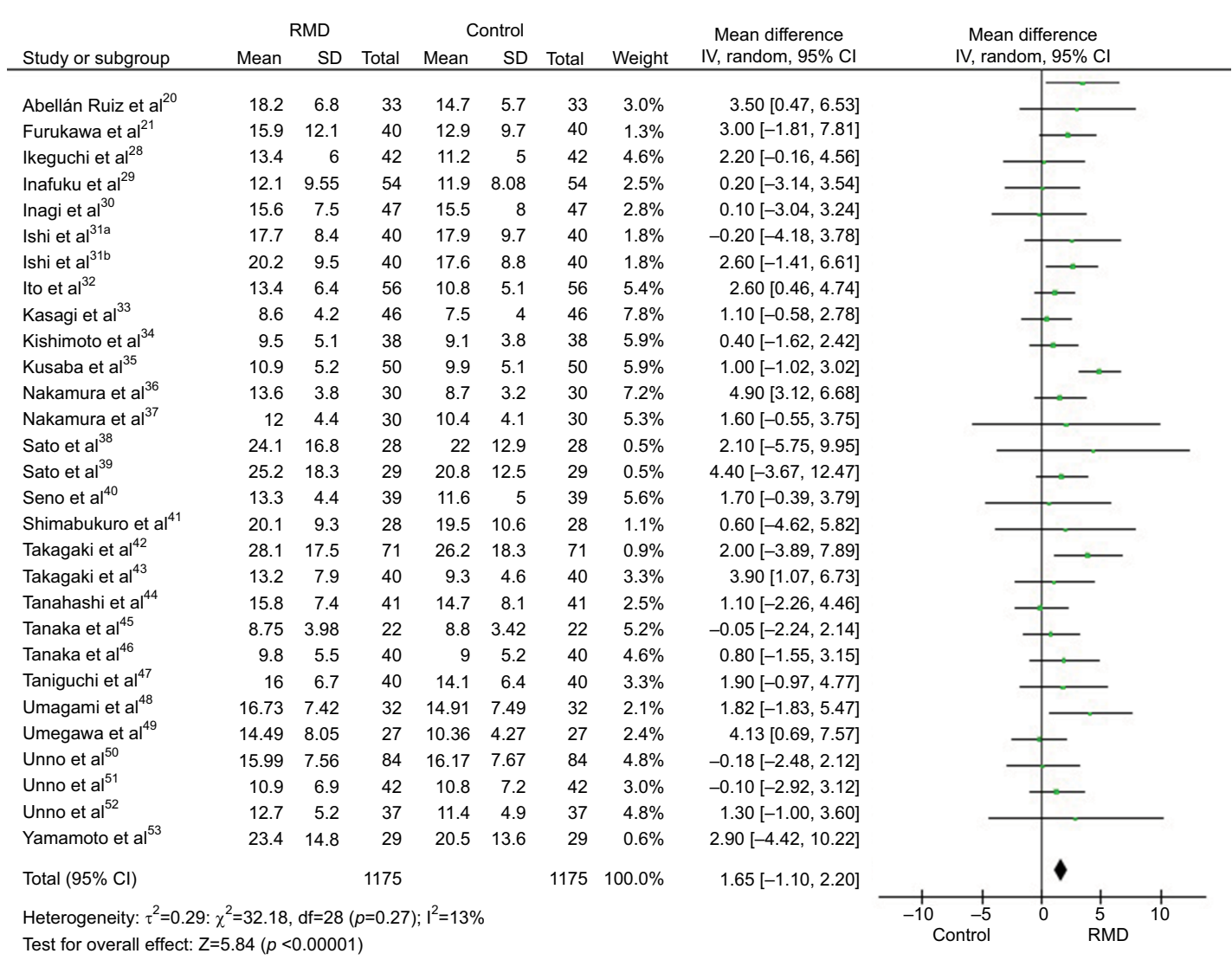

Figure 2 Forest plot for the effect of RMD on stool volume.

Abbreviations: RMD, resistant maltodextrin; IV, inverse variance.

$p<0.00001)$, and its heterogeneity was low $\left(I^{2}=34 \%, p=0.04\right.$; Figure 3$)$. These results indicate that RMD had a beneficial effect on bowel movements.

By visual judgment of the forest plot (Figures 2 and 3) and funnel plot (Figure 4) of 29 RCTs, it was estimated that the study by Nakamura et $\mathrm{al}^{36}$ was an outlier and affected heterogeneity. When this RCT was excluded and we analyzed 28 RCTs, the increase in stool volume was significant ( $\mathrm{MD}=1.38,95 \% \mathrm{CI}[0.85,1.90], p<0.00001)$, and there was no heterogeneity $\left(I^{2}=0 \%, p=0.89\right)$. The increase in stool frequency was also significant (MD $=0.62,95 \% \mathrm{CI}[0.44$, $0.80], p<0.00001)$ with no heterogeneity $\left(I^{2}=0 \%, p=0.54\right.$; figure not shown). While the MDs of both stool volume and stool frequency were slightly decreased by excluding the study of Nakamura et al, ${ }^{36}$ the beneficial effect of RMD on bowel movements was still statistically significant.

Regarding publication bias, the funnel plot of stool frequency was asymmetric; therefore, nine RCTs were added for correction by the trim and fill method (Figure 4). The increase in stool frequency was significant, and $\mathrm{MD}$ was even greater (MD $=0.95,95 \%$ CI $[0.73,1.17])$. Therefore, the effect of publication bias was not great.
Robustness of the results was evaluated by the fail-safe N. Fail-safe Ns for stool frequency and stool volume were 348 and 225, respectively, indicating that the effectiveness of RMD is significant unless there is further unpublished literature existing in more than the above mentioned numbers, concluding that RMD is ineffective. In conclusion, it appears that RMD has a beneficial effect on bowel movements.

\section{Secondary question: effects on subjective evaluation}

Subjective evaluation (consistency, color, odor of stool, and sensation of complete/incomplete evacuation) was conducted in 17 of 29 RCTs. In 13 of 17 extracted RCTs, higher scores indicated beneficial changes, and we conducted a metaanalysis of subjective evaluation on these 13 RCTs.

\section{Sensation of complete/incomplete evacuation}

The intake of RMD tended to improve the sensation of complete/incomplete evacuation compared with placebo intake (MD $=0.041,95 \%$ CI $[-0.007,0.088], p=0.096$ ), 


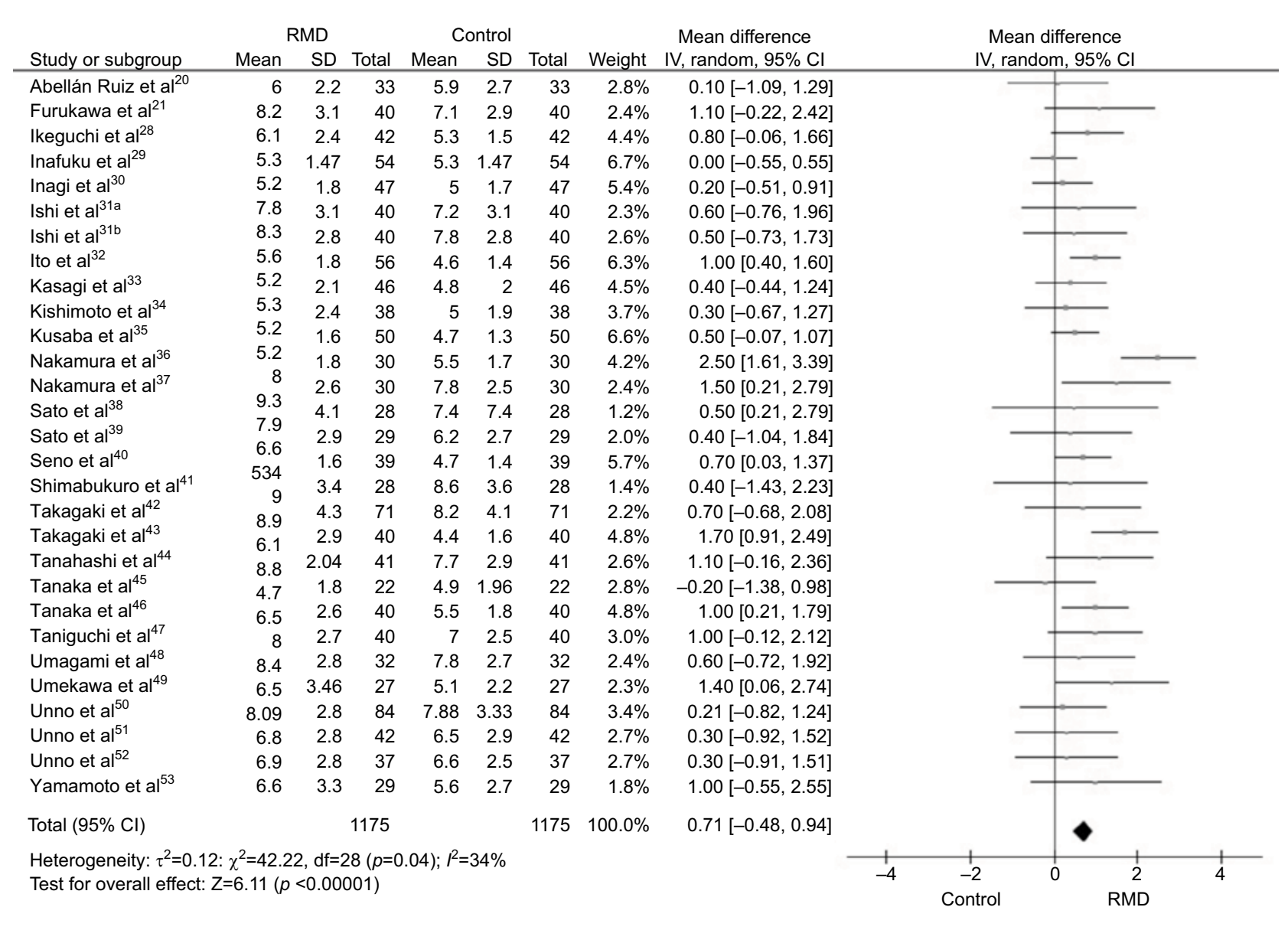

Figure 3 Forest plot for the effect of RMD on stool frequency.

Abbreviations: RMD, resistant maltodextrin; IV, inverse variance.

and heterogeneity was low $\left(I^{2}=0 \%, p=0.984\right.$; Figure 5$)$. The funnel plot (data not shown) of thirteen RCTs ${ }^{28,31,32,34,35,40,42}$ 43,45,46,51,52 was asymmetric; therefore, three negative data were added for correction by the trim and fill method. Failsafe $\mathrm{N}$ was not obtained as there was no significant difference. Publication bias was not high because no significant difference ( $p=0.49$ : two-sided test) was obtained by Egger regression, and the symmetry of the plot was not denied. No other significant difference was observed regarding subjective evaluation.

\section{Discussion}

The majority of the RCTs included in the preset systematic review were conducted in Japan. A number of studies on RMD have been conducted and published in Japan because RMD was first developed in that country and has been used in many FOSHU products. Food products recognized as FOSHU contain a key ingredient that provides a physiological function and benefit to health. To be accepted as a
FOSHU product by the Japanese governmental agency, an RCT should be conducted in humans to prove the efficacy of the functional ingredient, which needs to be published in a peer-reviewed journal. ${ }^{54}$ Therefore, many scientific papers reporting the efficacy of food products containing RMD have been published in Japan. A meta-analysis of RCTs with foods containing RMD was conducted to determine the effect of RMD on postprandial blood glucose elevation and concluded that RMD attenuated the glycemic response to foods. ${ }^{55}$ As many RMD studies were published in Japanese scientific journals, terms related to bowel movements were used to narrow the search in Japanese. As there were limited studies published in English, it was possible to screen the relevant papers on the basis of the titles and abstracts. Therefore, the terms related to RMD and their variations were used for the search in English.

The present study revealed that both stool frequency and stool volume were significantly increased by RMD intake compared with placebo. Although the meta-analysis of the 
A

Funnel plot of standard error by difference in means

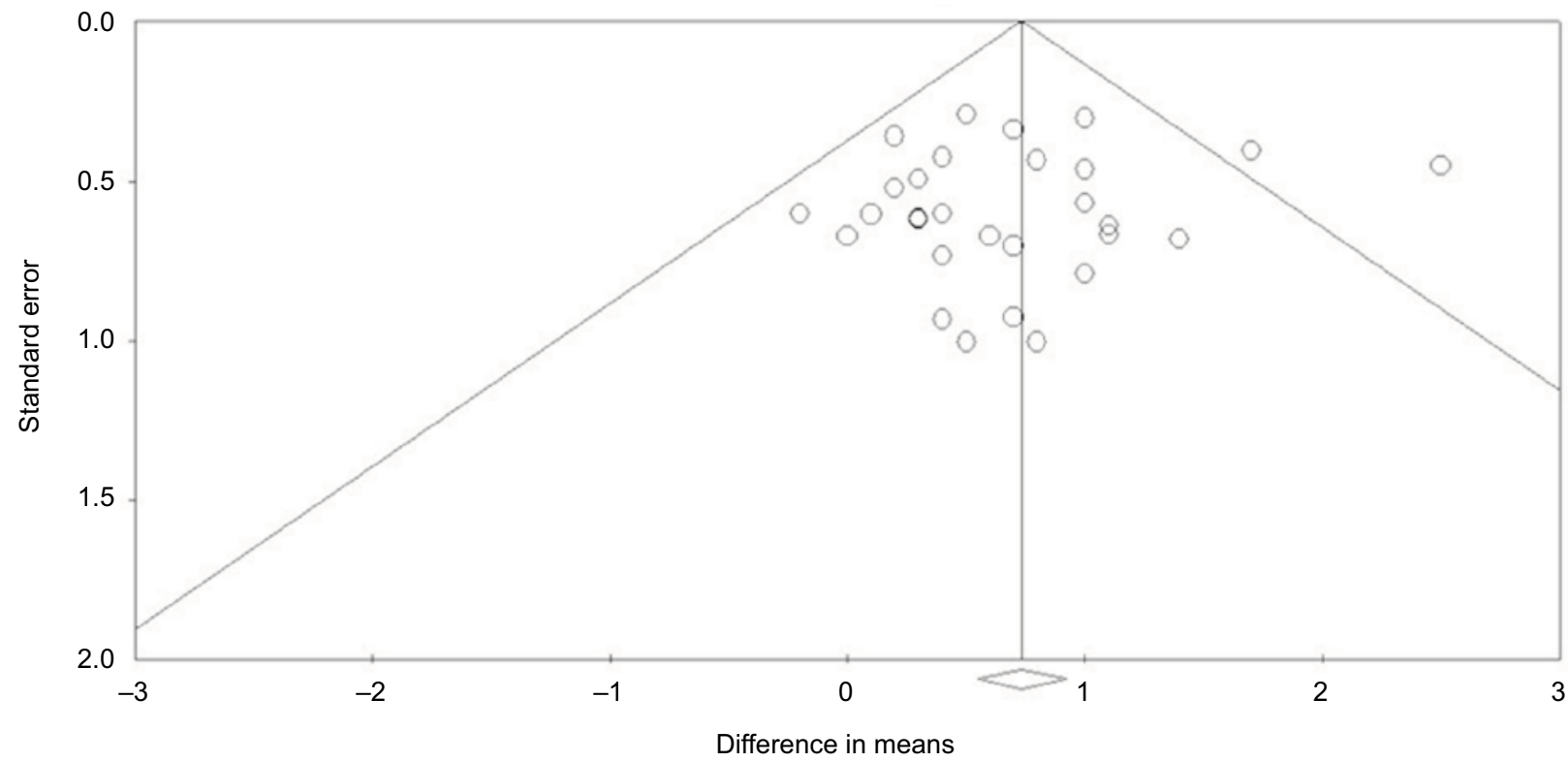

B

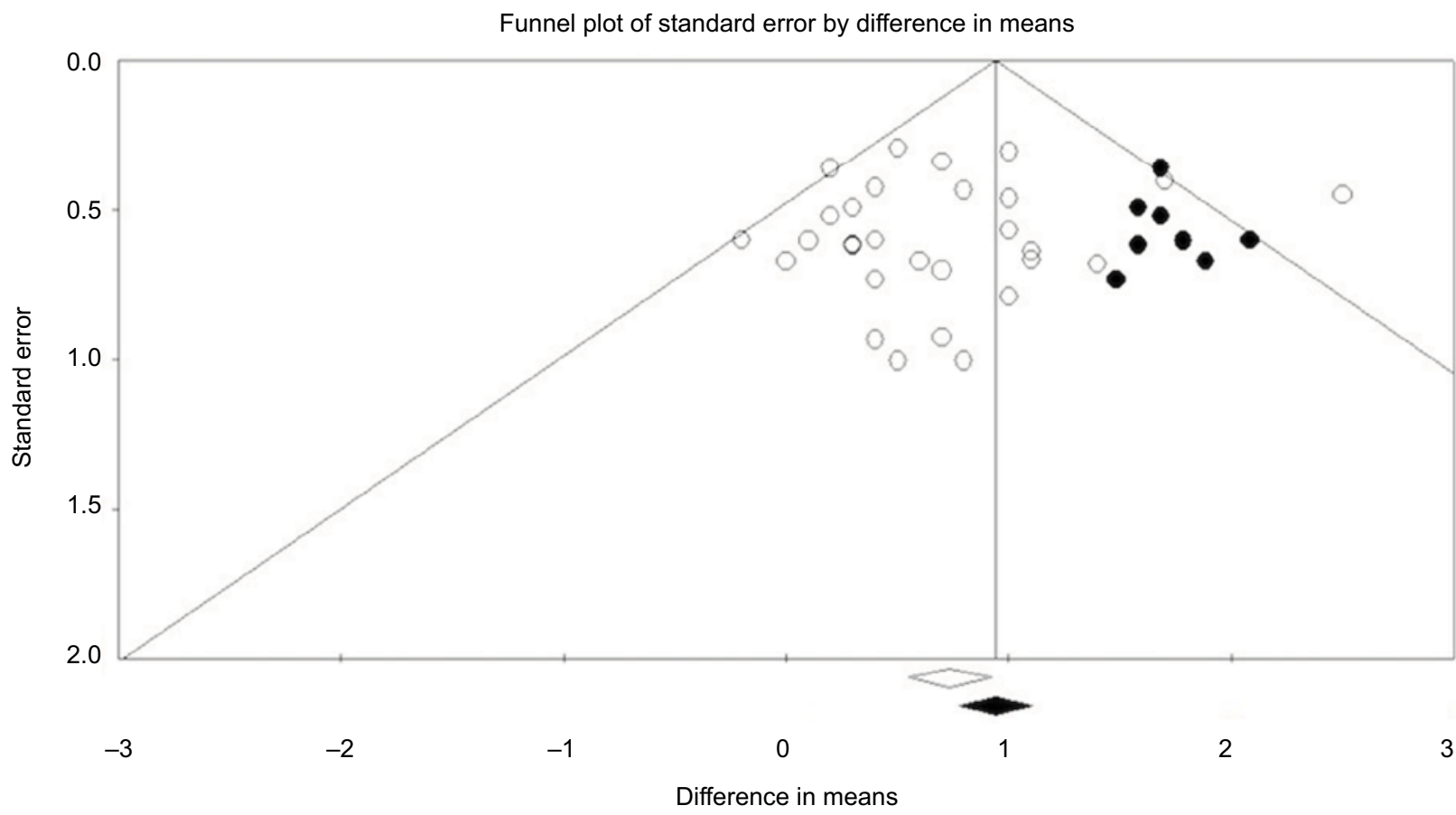

Figure 4 Funnel plot of publication bias for the effect of RMD on stool frequency.

Notes: (A) Original data; (B) after correction by the trim and fill method.

Abbreviation: RMD, resistant maltodextrin.

29 RCTs revealed the significance of RMD, the heterogeneity $\left(I^{2}\right)$ values for stool volume and stool frequency were $13 \%$ and $34 \%$, respectively. This indicated that one extreme outcome may have affected all the results. Therefore, we conducted a further meta-analysis excluding the outlier (Nakamura et $\mathrm{al}^{36}$ ); heterogeneity for both stool volume and stool frequency was $0 \%$, and the significant effect of RMD remained. These results confirmed that the effect of RMD on bowel movements was significant even after deleting the outlier from the analysis.

Of the 29 RCTs, 10 RCTs were double-blinded, 18 RCTs were single-blinded, and one RCT did not report 


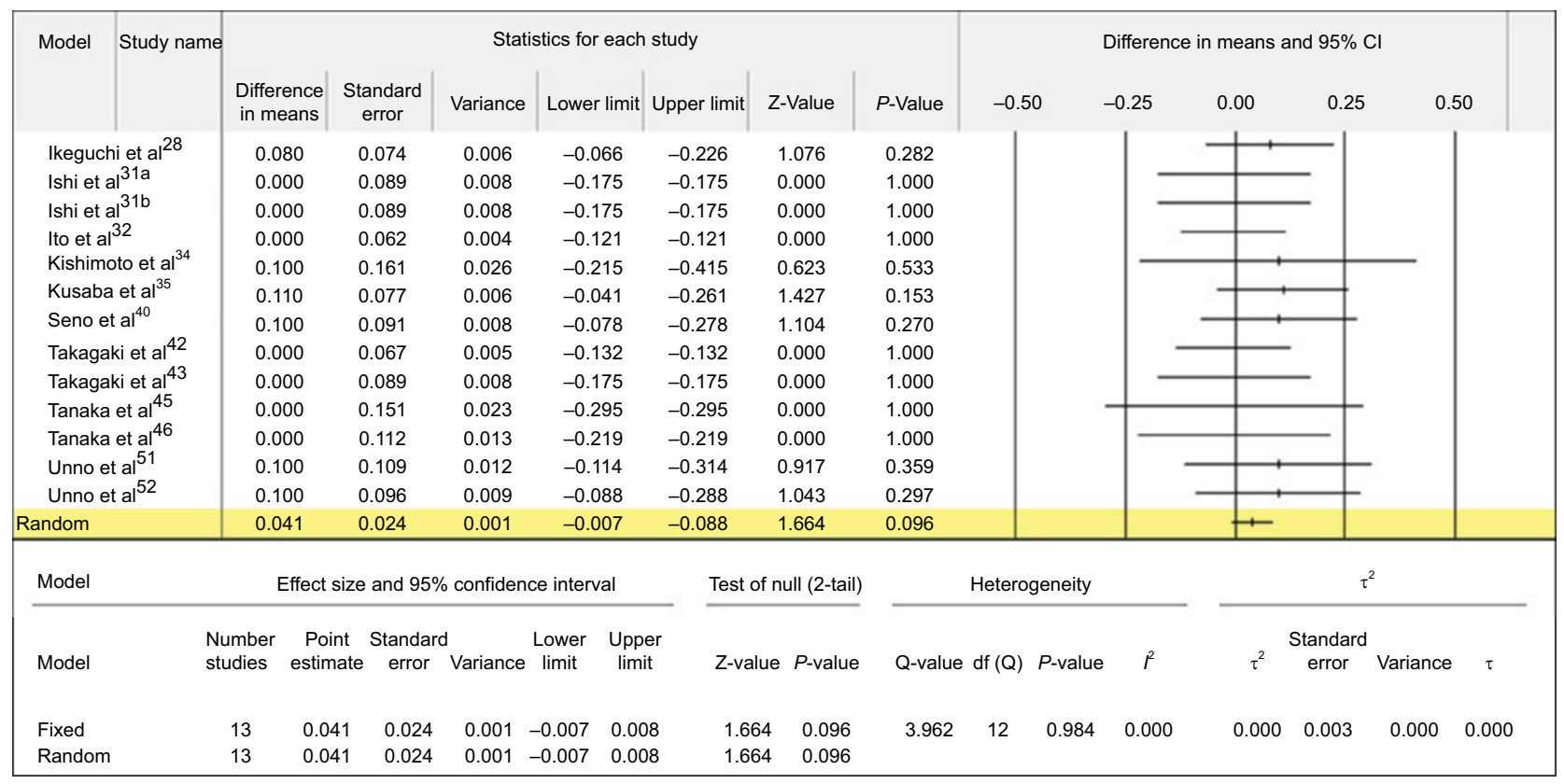

Figure 5 Forest plot for the effect of RMD on the sensation of complete/incomplete evacuation.

Abbreviation: RMD, resistant maltodextrin.

blinding. Therefore, 19 RCTs were classified as "unclear risk" because they were not double-blinded. However, we evaluated that the risk of bias was low as the 19 RCTs were conducted as placebo-controlled trials. As a result of the evaluation of the publication bias, nine RCTs for stool frequency were added, based on the correction by the trim and fill method, which corroborated the hypothesis regarding the beneficial effect on bowel movements. Ten double-blinded RCTs were selected, and the meta-analysis was performed. Increases in stool volume and stool frequency were significant. The failsafe Ns were over 200 for both stool frequency and stool volume, which means that the positive effect of RMD on bowel movements is significant unless there are over 200 unpublished papers, concluding that RMD has no effect. We searched the following clinical trial registration systems to identify any relevant unpublished papers: University Hospital Medical Information Network Center (http://www.umin.ac.jp/), Clinical Trials. Gov (https:// clinicaltrials.gov/), International Clinical Trials Registry Platform (http://apps.who.int/trialsearch/Default.aspx), and International Standard Randomised Controlled Trial Number Register (https://www.isrctn.com/). We found no registered clinical trials for the effect of RMD on bowel movements, indicating that there were no unpublished papers. Therefore, the effect of publication bias was not high, which strongly supports the effect of RMD on improving bowel movements.

It is known that the contents of the large intestine (ie, stool) are transported by the peristalsis and excreted. Peristaltic activity is induced by the gastrocolic reflex, which occurs when foods enter the stomach, and by the physical stimulus of the stool volume. Peristaltic activity is also stimulated by acetic acid, propionic acid, and butyric acid. ${ }^{56}$ These shortchain fatty acids (SCFAs) are produced by intestinal bacterial fermentation. Ingested RMD reaches the large intestine, where RMD is fermented by intestinal bacteria and SCFAs are produced. ${ }^{57}$ SCFAs produced in the large intestine stimulate mucosa of the large intestine and promote peristaltic activity. Intestinal bacteria proliferate by degrading RMD and increase in number. ${ }^{16} \mathrm{It}$ is postulated that peristaltic activity is promoted by the physical stimulus of increased stool volume, including increased intestinal bacteria and undigested RMD. Intake of RMD has been reported to shorten gastrointestinal transit time and improve stool volume and stool consistency in humans. ${ }^{20}$

Regarding the secondary question examined in this study, the sensation of complete/incomplete evacuation tended to be improved by RMD intake compared with placebo intake $(p=0.096)$. Straining during defecation, 
sensation of incomplete evacuation, and sensation of anorectal obstruction/blockage are caused by hard stool and defined by the Rome III diagnostic criteria. Hard stool is caused by prolonged gastrointestinal transit time and reduced stool moisture, which is absorbed from the intestinal wall. RMD intake shortens the gastrointestinal transit time, with defecation of softer stools that retain moisture. Consequently, the sensation of complete/incomplete evacuation is improved.

Twenty-eight of 29 RCTs (except for the study of Abellán Ruiz et $\mathrm{al}^{20}$ ) were conducted by the crossover comparison method. The crossover comparison method can eliminate individual differences and can make it possible to estimate the effect with a small number of subjects. However, if the washout period is insufficient, a carryover effect occurs, which affects the result. In the 28 RCTs, the washout period range was between 7 and 14 days, and the average was 9.9 days. In general, normal bowel movements will be passed between 24 and 72 hours after foods are ingested. Breath hydrogen gas, a marker of intestinal fermentation, was not detected at the 24-hour time point after RMD intake, ${ }^{58}$ indicating that RMD is fermented and/or excreted within 24 hours. Therefore, it is unlikely that there were studies with carryover effects among the 28 RCTs, and it is considered that the washout periods were appropriate.

Some systematic reviews on bowel movements have been reported regardless of raw materials and properties of dietary fibers. Yang et $\mathrm{al}^{59}$ conducted a meta-analysis of five RCTs on bowel movements by the ingestion of different dietary fibers (glucomannan, wheat bran, and cocoa husk) and concluded that stool frequency was significantly increased by the intake of dietary fibers. de Vries et $\mathrm{al}^{60}$ conducted meta-analyses to evaluate the effect of dietary fibers derived from cereals on bowel movements, based on the raw material, and reported that the intake of dietary fiber derived from wheat significantly increased stool volume, stool frequency, and stool moisture and significantly shortened the gastrointestinal transit time. All these meta-analyses involved natural and unprocessed dietary fibers. In the current meta-analysis study, we investigated dietary fibers manufactured from starch, ie, RMD, which has been used in the processed food market worldwide. The results based on the RCTs focusing only on human subjects suggested that RMD improves bowel movements. Therefore, in relation to bowel movements, RMD effectively works in the same way as unprocessed dietary fibers.
Baer et $\mathrm{al}^{61}$ observed increased wet and dry stool weight by RMD intake (25 and $50 \mathrm{~g}$ ) in a dose-dependent relation. Satouchi et $\mathrm{al}^{62}$ observed that RMD intake (3.0 and $5.9 \mathrm{~g}$ ) increased both stool frequency and stool volume. Both RCTs were not included in the present study as the former RCT reported stool volume by weight, and the latter RCT did not have a placebo group. However, these two RCTs showed that the intake of RMD increases both stool volume, by weight, and stool frequency, dose-dependently. Meanwhile, there is a concern that transient diarrhea may be caused by the intake of large doses of indigestible saccharides. When indigestible saccharides flow into the large intestine in high volume at once, osmotic pressure will be increased. To decrease the pressure, water is pumped into the intestinal tract and transient diarrhea occurs. The relevant doses differ according to the specific substances. The maximum no-effect level of RMD ( $1.0 \mathrm{~g} / \mathrm{kg}$ body weight for men and $1.1 \mathrm{~g} / \mathrm{kg}$ body weight for women $)^{63}$ is higher than that of lactitol $(0.075 \mathrm{~g} / \mathrm{kg}$ for men and $0.15 \mathrm{~g} / \mathrm{kg}$ for women $)^{64}$ and galactooligosaccharide $(0.3 \mathrm{~g} / \mathrm{kg}$ for men and $0.3 \mathrm{~g} / \mathrm{kg}$ for women $) .{ }^{65}$ The intake of RMD in the present study ranged from $3.8 \mathrm{~g}$ to $13.5 \mathrm{~g}$ per day. It has been postulated that the common use of RMD rarely causes transient diarrhea.

Currently, there are several companies producing RMD from different raw materials and/or by different manufacturing processes. Therefore, dietary fiber content, molecular structure, and/or disposition in the human body could differ among products. We conducted a meta-analysis for the effect of RMD on bowel movements irrespective of the raw material and the manufacturing process. We identified some papers regarding RMD manufactured by different processes during the literature search. However, some were animal studies, and others had different objectives, which did not meet the study criteria and were finally eliminated. Consequently, all the papers adopted in the current study involved the same RMD product. There are different RMD products available on the market with different physical and physiological properties; therefore, further studies are required to investigate the differences in efficacy of each RMD product on different physiological functions, including the effect on bowel movements.

Regular bowel movements are an important factor affecting the quality of healthy life and could be achieved by consuming more dietary fiber and performing moderate exercise. When the intake of dietary fiber is not sufficient, the use of foods containing RMD is a practical strategy, which could contribute to normal bowel function. 


\section{Conclusion}

The intake of RMD significantly increased stool volume and stool frequency compared with placebo intake. RMD intake tended to improve the sensation of complete/incomplete evacuation. Therefore, RMD improves bowel movements and contributes to normal bowel function.

\section{Acknowledgments}

The present study was conducted and funded by Matsutani Chemical Industry Co., Ltd. (MCI). MCI is involved in the production and distribution of RMD.

\section{Disclosure}

YY is an employee of MCI. The authors report no other conflicts of interest directly relevant to the content of this paper.

\section{References}

1. Higgins PD, Johanson JF. Epidemiology of constipation in North America: a systematic review. Am J Gastroenterol. 2004;99(4):750-759.

2. Sonnenberg A, Koch TR. Epidemiology of constipation in the United States. Dis Colon Rectum. 1989;32(1):1-8.

3. Jarrett ME, Mowatt G, Glazener CM, et al. Systematic review of sacral nerve stimulation for faecal incontinence and constipation. Br J Surg. 2004;91(12):1559-1569.

4. Comprehensive Survey of Living Conditions, Japan, 2013, Ministry of Health, Labour and Welfare, (2014). Available from: http://www. mhlw.go.jp/toukei/list/d1/20-21-h25.pdf. Accessed March 1, 2017. Japanese.

5. Drossman DA. The functional gastrointestinal disorders and the Rome III process. Gastroenterology. 2006;130(5):1377-1390.

6. Sun SX, Dibonaventura M, Purayidathil FW, Wagner JS, Dabbous O, Mody R. Impact of chronic constipation on health-related quality of life, work productivity, and healthcare resource use: an analysis of the National Health and Wellness Survey. Dig Dis Sci. 2011;56(9): 2688-2695.

7. Watanabe T, Nakaya N, Kurashima K, Kuriyama S, Tsubono Y, Tsuji I. Constipation, laxative use and risk of colorectal cancer: the Miyagi Cohort Study. Eur J Cancer. 2004;40(14):2109-2115.

8. Chang JY, Locke GR 3rd, McNally MA, et al. Impact of functional gastrointestinal disorders on survival in the community. Am J Gastroenterol. 2010;105(4):822-832.

9. Cho SS, Dreher ML, editors. Handbook of Dietary Fiber (Food Science and Technology). New York, NY: Marcel Dekker, Inc.; 2001.

10. Burkitt DP. Epidemiology of cancer of the colon and rectum. Cancer. 1971;28(1):3-13.

11. Scientific opinion on dietary reference values for carbohydrates and dietary fibre [homepage on the Internet]. Available from: http://www. efsa.europa.eu/sites/default/files/scientific_output/files/main_documents/1462.pdf. Accessed March 1, 2017.

12. Elmadfa I, Meyer A, Nowak V, et al. European Nutrition and Health Report 2009. Forum Nutr. 2009;62:1-405.

13. U.S. Department of Agriculture; U.S. Department of Health and Human Services. Dietary Guidelines for Americans, 2010. 7th ed. Washington, DC: U.S. Government Printing Office; 2010.

14. National Health and Nutrition Survey Japan, 2014, Ministry of Health, Labour and Welfare, (2015). Available from: http://www. mhlw.go.jp/file/04-Houdouhappyou-10904750-KenkoukyokuGantaisakukenkouzoushinka/kekkagaiyou_7.pdf. Accessed March 1, 2017. Japanese.
15. Cummings JH, Branch W, Jenkins DJ, Southgate DA, Houston H, James WP. Colonic response to dietary fibre from carrot, cabbage, apple, bran. Lancet. 1978;1(8054):5-9.

16. Fastinger ND, Karr-Lilienthal LK, Spears JK, et al. A novel resistant maltodextrin alters gastrointestinal tolerance factors, fecal characteristics, and fecal microbiota in healthy adult humans. $J$ Am Coll Nutr. 2008;27(2):356-366.

17. Graham DY, Moser SE, Estes MK. The effect of bran on bowel function in constipation. Am J Gastroenterol. 1982;77(9):599-603.

18. Shen D, Bai H, Li Z, Yu Y, Zhang H, Chen L. Positive effects of resistant starch supplementation on bowel function in healthy adults: a systematic review and meta-analysis of randomized controlled trials. Int $J$ Food Sci Nutr. 2017;68(2):149-157.

19. Yamada K, Sato-Mito N, Nagata J, Umegaki K. Health claim evidence requirements in Japan. J Nutr. 2008;138(6):1192S-1198S.

20. Abellán Ruiz MS, Barnuevo Espinosa MD, Contreras Fernández CJ, et al. Digestion-resistant maltodextrin effects on colonic transit time and stool weight: a randomized controlled clinical study. Eur J Nutr. 2016;55(8):2389-2397.

21. Furukawa T, Yonekawa S, Kurosawa M. [Effects of prepared cocoa powder containing indigestible dextrin on human defecation]. $J$ Jpn Council Advanced Food Ingred Res. 2004;7:55-62. Japanese.

22. McRorie JW, Chey WD. Fermented fiber supplements are no better than placebo for a laxative effect. Dig Dis Sci. 2016;61(11):3140-3146.

23. Higgins JPT, Green S. Cochrane Handbook for Systematic Reviews of Interventions. Chichester: John Wiley \& Sons; 2009.

24. Liberati A, Altman DG, Tetzlaff J, et al. The PRISMA statement for reporting systematic reviews and meta-analyses of studies that evaluate healthcare interventions: explanation and elaboration. $B M J$. 2009;339:b2700.

25. Ikeguchi M, Ariura Y, Takagaki K, Ishibashi Y, Inagawa A, SugawaKatayama Y. [Effects of young barley leaf powder on fecal weight and fecal microflora in healthy women]. J Jpn Assoc Dietary Fiber Res. 2004;8(2):93-103. Japanese.

26. Guidance on the scientific requirements for health claims related to the immune system, the gastrointestinal tract and defence against pathogenic microorganisms. EFSA Panel on Dietetic Products, Nutrition and Allergies (NDA). EFSA Journal. 2016;14(1):4369. Available from: http://onlinelibrary.wiley.com/doi/10.2903/j.efsa.2016.4369/epdf. Accessed March 1, 2017.

27. Points to be considered preparing application for Foods for Specified Health Use. Consumer Affairs Agency, Government of Japan. (2014): Available from: http://www.caa.go.jp/foods/pdf/syokuhin1567.pdf. Accessed March 1, 2017. Japanese.

28. Ikeguchi M, Kobayashi M, Ariura Y, et al. [Effects of drink powder containing indigestible dextrin on defecation frequency and fecal characteristics of women with weak constipation]. J Jpn Council Advanced Food Ingred Res. 2003;6:67-75. Japanese.

29. Inafuku K, Sasaki T, Ikehara Y, et al. [Effects of powdered drink containing indigestible dextrin on defecation with low-grade constipation tendency and the safety of its excessive intake]. $J$ Nutr Food. 2004;7:1-15. Japanese.

30. Inagi M, Fujii S, Iino H. [Effects of the administration of soft drink containing indigestible dextrin on defecation frequency and fecal characteristics of Japanese healthy female volunteers]. J Nutr Food. 1999;2(1):44-51. Japanese.

31. Ishi S, Kato K, Kusuhara S. [Effects of rice crackers containing indigestible dextrin on female defecation]. J Nutr Food. 2000;3(2):37-44. Japanese.

32. Ito S, Kusaba N, Ito M, et al. [Effects of AOJIRU drink powder of sweet potato leaf containing indigestible dextrin on defecation in volunteers with constipation]. Jpn Pharmacol Ther. 2007;35:399-405. Japanese.

33. Kasagi T, Urakami K, Taniguchi M, et al. [Effects of tea beverage containing indigestible dextrin on defecation of healthy male and female students]. Journal of the Yonago Medical Association. 2004;55:153-159. Japanese. 
34. Kishimoto M, Unno T, Tanaka Y. [The effects of a dessert beverage supplemented with indigestible dextrin on defecation and health conditions in female students]. J Jpn Assoc Dietary Fiber Res. 2007;11(1):23-31. Japanese.

35. Kusaba N, Kamiya T, Ikeguchi M, et al. [Effects of AOJIRU drink powder of angelica keiskei leaf containing indigestible dextrin on defecation in volunteers with constipation]. Jpn Pharmacol Ther. 2008;36:1159-1165. Japanese.

36. Nakamura T, Kawabata Y, Noda F, et al. [Effects of crac flavor kamaboko containing indigestible-dextrin on defecation]. J Nutr Food. 2002;5:11-20. Japanese.

37. Nakamura T, Nitta K, Kawabata $Y$, et al. [Effects of chikuwa containing indigestible dextrin on defecation in healthy female students]. $J$ Nutr Food. 2005;8:17-25. Japanese.

38. Sato M, Oishi Y, Ohmori T, et al. [Effect of cooked and cured loin-roll ham containing indigestible dextrin on fecal amount and defecation frequency]. J Nutr Food. 2000;3(4):47-54. Japanese.

39. Sato M, Oishi Y, Ohmori T, et al. [Effect of sausage containing indigestible dextrin on fecal amount and defecation frequency]. $J$ Nutr Food. 2000;3(4):55-62. Japanese.

40. Seno K, Kumagai T, Watanabe T. [Effects of instant miso-soup with indigestible dextrin on defecation and fecal characteristics in healthy adults, and effects of excess intake on abdominal symptoms]. $J$ Nutr Food. 2004;7:65-77. Japanese.

41. Shimabukuro C, Inoue T, Misumi S. [The effects of ingestion of beverage supplemented with indigestible dextrin on human defecation]. J Nutr Food. 2002;5:1-9. Japanese.

42. Takagaki K, Ikeguchi M, Ariura Y, Fujinaga N, Ishibashi Y, SugawaKatayama Y. [The effects of AOJIRU drink powder containing indigestible dextrin on defecation frequency and fecal characteristics]. $J$ Nutr Food. 2001;4(4):29-35. Japanese.

43. Takagaki K, Ikeguchi M, Ariura Y, et al. [Effects of AOJIRU drink powder containing indigestible dextrin on defecation frequency and fecal characteristics of women with weak constipation]. J Jpn Council Advanced Food Ingred Res. 2002;5:19-23. Japanese.

44. Tanahashi H, Hikasa M, M, Fukushima A, et al. [Effects of drink containing indigestible dextrin in women]. J Nutr Food. 2003;6:11-19. Japanese.

45. Tanaka K, Mizutani H, Yamada S, Iwata Y, Katada T, Nakata S. [Beneficial effect of a vegetable drink containing indigestible dextrin on defecation in women with constipation]. J Nutr Food. 2000;3:39-45. Japanese.

46. Tanaka K, Mizutani H, Yamada S, Iwata Y, Katada T, Nakata S. [Effect of vegetable drink containing indigestible dextrin on defecation]. J Nutr Food. 2002;5:11-21. Japanese.

47. Taniguchi O, Kurihara S, Morioka T, et al. [Effect of the ingestion of indigestible dextrin added jelly on the defecation of healthy male and female volunteers]. J Nutr Food. 2002;5:11-20. Japanese.

48. Umagami M, Kai A, Mizuta A, et al. [Effect on human defecation, and safety for healthcare food by the ingestion of vegetable powder processed food containing indigestible dextrin]. Jpn J Nutr Assessment. 2004;21:483-490. Japanese.
49. Umekawa T, Fujii K, Matsuoka T. [Effect of drinks supplemented with indigestible-dextrin on fecal amount]. J Nutr Food. 1999;2:52-57. Japanese.

50. Unno T, Nagata K, Yayabe F, Horiguchi T. [Effect of drinks supplemented with indigestible dextrin on defecation in human]. J Nutr Food. 2000;3:31-38. Japanese.

51. Unno T, Nagata K, Suzuki N, Yayabe F, Horiguchi T. [Effect of a vegetable drink supplemented with indigestible dextrin on defecation in females]. J Nutr Food. 2001;4:21-27. Japanese.

52. Unno T, Kikuchi T, Nagata K. [Effect of a mixed juice of fruit and vegetable containing indigestible dextrin on defecation in human subjects]. J Jpn Council Advanced Food Ingred Res. 2004;6:23-27. Japanese.

53. Yamamoto Y, Nishida T, Sone Y. [The effect of ingestion of beverage supplemented with indigestible dextrin on human defecation]. J Nutr Food. 2000;3(2):29-36. Japanese.

54. Overview of Foods for Specified Health Use. Consumer Affairs Agency, Government of Japan. Available from: http://www.caa.go.jp/foods/pdf/ syokuhin86.pdf. Accessed March 1, 2017. Japanese.

55. Livesey G, Tagami H. Interventions to lower the glycemic response to carbohydrate foods with a low-viscosity fibre (resistant maltodextrin): meta-analysis of randomized controlled trials. Am J Clin Nutr. 2009;89(1):114-125.

56. Cummings JH, Rombeau JL, Sakata T. Physiological and clinical aspects of short-chain fatty acids. Gut. 1996;38(1):156-157.

57. Miyazato S, Nakagawa C, Kishimoto Y, Tagami H, Hara H. Promotive effects of resistant maltodextrin on apparent absorption of calcium, magnesium, iron and zinc in rats. Eur J Nutr. 2010;49(3):165-171.

58. Goda T, Kajiya Y, Suruga K, Tagami H, Livesey G. Availability, fermentability, and energy value of resistant maltodextrin: modeling of short-term indirect calorimetric measurements in healthy adults. Am J Clin Nutr. 2006;83(6):1321-1330.

59. Yang J, Wang HP, Zhou L, Xu CF. Effect of dietary fiber on constipation: a meta analysis. World J Gastroenterol. 2012;18(48):7378-7383.

60. de Vries J, Miller PE, Verbeke K. Effects of cereal fibre on bowel function: a systematic review of intervention trials. World J Gastroenterol. 2015;21(29):8952-8963.

61. Baer DJ, Stote KS, Henderson T, et al. The metabolizable energy of dietary resistant maltodextrin is variable and alters fecal microbiota composition in adult men. $J$ Nutr. 2014;144(7):1023-1029.

62. Satouchi M, Wakabayashi S, Ohkuma K, Fujiwara K, Matsuoka A. [Effects of indigestible dextrin on bowel movements]. Jpn J Nutr Dietetics. 1993;51(1):31-37. Japanese.

63. Kishimoto Y, Kanahori S, Sakano K, Ebihara S. The maximum single dose of resistant maltodextrin that does not cause diarrhea in humans. J Nutr Sci Vitaminol (Tokyo). 2013;59(4):352-357.

64. Koizumi N, Ninomiya R, Fujita D. [Estimation of maximum no-effect dose of orally ingested hydrogenated lactose (lactitol) in humans]. Jpn J Food Chem. 1997;4(1):27-32. Japanese.

65. Kimura M, Ikeda M, Shibata H, Ikeda S, Mastumoto K. [Evaluating the laxative threshold and safety of galactooligosaccharide syrup]. Jpn J Food Chem. 2004;11:67-74. Japanese.
Clinical and Experimental Gastroenterology

\section{Publish your work in this journal}

Clinical and Experimental Gastroenterology is an international, peerreviewed, open access, online journal publishing original research, reports, editorials, reviews and commentaries on all aspects of gastroenterology in the clinic and laboratory. This journal is included on PubMed. The manuscript management system is completely online

\section{Dovepress}

and includes a very quick and fair peer-review system, which is all easy to use. Visit http://www.dovepress.com/testimonials.php to read real quotes from published authors. 